\title{
Medidas morfométricas para avaliação da qualidade dos cascos de novilhas Holandesas
}

Bruno Alcantara Sampaio Pinto ${ }^{[a]}$, Muriel Magda Lustosa Pimente ${ }^{[b]}$, Regina Valéria da Cunha Dias ${ }^{\left[c^{0}\right.}$, Tatiana Leite Barbosa Araújo dos Santos ${ }^{[c]}$, Felipe Venceslau Câmara ${ }^{[d]}$, Rivaldo Bruno Medeiros de Lucena ${ }^{\left[{ }^{[]}\right.}$, Ilanna Vanessa Pristo de Medeiros Oliveira[c]

\author{
[a] Médico veterinário \\ [b] Centro Universitário Cesmac (CESMAC), Maceió, AL, Brasil \\ [c] Universidade Federal Rural do Semi-Árido (UFERSA), Mossoró, RN, Brasil

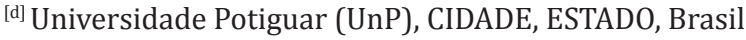

*Autor correspondente

e-mail: regina@ufersa.edu.br

\section{Resumo}

Medidas de tamanho e conformação são utilizadas para definir a qualidade e verificar a saúde dos cascos bovinos. Este estudo objetivou verificar a morfologia dos dígitos de novilhas e avaliar se estas apresentam ou estão predispostas a lesões. Utilizou-se 15 novilhas da raça Holandesa, criadas sob sistema semiintensivo, na Universidade Federal Rural do Semi-Árido. Os cascos foram higienizados com água corrente e escova. 0 podogoniômetro foi utilizado para avaliar os parâmetros: altura de talão (AT), altura de casco (AC), comprimento da parede dorsal do casco (CP), comprimento da sola (CS), comprimento diagonal (CD) e ângulo dorsal (AP). Os dados foram avaliados utilizando-se média aritmética, desvio padrão, coeficiente de variação, variância, mínimo e máximo, porcentagem e qui-quadrado, teste t de Student para comparações múltiplas. Todas as análises foram realizadas considerando nível de significância de 5\%. Os dados AP não apresentaram diferença estatística $(\mathrm{P}<0,05)$ quando comparados aos dígitos das novilhas com ou sem deformidade. Na AT, os dígitos laterais esquerdos ( $\mathrm{P}=0,03 ; \mathrm{P}=0,03)$, laterais direitos $(\mathrm{P}=0,04 ; \mathrm{P}=0,00) \mathrm{e}$ mediais direitos $(\mathrm{P}=0,05 ; \mathrm{P}=0,00)$ dos membros torácicos e pélvicos apresentaram diferença estatística. Com o passar dos anos, o talão mais alto da unha lateral posterior resultará num maior sustento do peso corporal, justificando-se a diferença estatística encontrada na AT das novilhas estudadas. O CP apresentou diferenças nos dígitos lateral esquerdo $(P=0,01)$, medial esquerdo $(P=0,02)$ e medial direito $(P=0,04)$ do membro torácico, e lateral esquerdo $(\mathrm{P}=0,04)$ do membro pélvico. Sabe-se que o ambiente influencia nos valores de $\mathrm{CP}$, e as novilhas deste estudo eram criadas em solo de areia compactada, ocasionando o enrijecimento do estojo córneo e menor desgaste. $\mathrm{Na} A C$, os dígitos lateral direito $(\mathrm{P}=0,00)$, medial direito 
$(P=0,01)$ do membro torácico e o dígito lateral esquerdo $(P=0,00)$ do membro pélvico apresentaram diferenças para novilhas com ou sem alterações digitais. O CS apresentou diferença significativa do dígito medial direito $(P=0,00)$ do membro torácico. No $C D$, os dígitos lateral esquerdo e direito $(P=0,04 ; P=0,01)$, medial esquerdo e direito $(\mathrm{P}=0,02 ; \mathrm{P}=0,01)$ dos membros torácicos e o dígito lateral direito $(\mathrm{P}=0,04)$ do membro pélvico obtiveram diferença para novilhas com ou sem alterações morfológicas. Para novilhas, os principais fatores que influenciam o crescimento excessivo desses dígitos são idade, peso, genética e manejo. Esses fatores estão correlacionados, sendo importantes para o equilíbrio podal. 